\title{
The effect of statin treatment on survival and on the use of healthcare resources among patients with acute myocardial infarction
}

\author{
LIEN NGUYEN 1 , * \\ UNTO HÄKKINEN ${ }^{1}$ \\ HENNA JURVANEN ${ }^{1}$ \\ ${ }^{1}$ Centre for Health and Social Economics - CHESS, National Institute for Health and Welfare (THL), \\ Helsinki, Finland
}

\begin{abstract}
The aim of this study was to investigate the cost-effectiveness of statin use by newly hospitalised patients with acute myocardial infarction (AMI) in Finland. The data were from the PERFECT database of patients hospitalised for AMI and discharged in 1998-2012 in Finland. Selected patients had first-time AMI and had not used statins earlier ( $\mathrm{N}=60404)$. We generated a matched data set from statin non-users for statin users based on propensity matching analysis ( $\mathrm{N}=28 \mathrm{412}$ ), which was also used. Statin use was defined as statins purchased within the first week after hospital discharge. Healthcare costs included costs of inpatient and outpatient hospital care, costs of nursing homes and costs of prescribed medicines (at 2011 prices). The follow-up time was one year. Logit and generalised linear models were used. We measured the effects of statin use as life years (LYs) gained and computed costs per LY gained. Both data were analysed for the entire period and for subperiods 1998-2001, 2002-2007 and 2008-2011, without discount rates and with a $3 \%$ discount rate. An average patient would gain $0.26-0.51$ more years. The estimated costs per LY gained ranged between EUR 800 and 15000 . They were highest (EUR 12 000-15 000) in 1998-2001 by the matched data, but were actually savings in 2008-2011. The estimated costs indicate that statin use in treating AMI was very cost-effective. However, our rather long study period may suggest that the cost estimates per LY gained could be overestimated, as the life expectancy of AMI patients is likely shorter than that of the general population.
\end{abstract}

JEL classification: I12, J18, D6

Key words: statin use, acute myocardial infarction AMI, cost-effectiveness, mortality, healthcare costs, PERFECT

\section{Introduction}

Cardiovascular diseases (CVD) are the leading cause of death worldwide. While coronary heart disease (CHD) is the most frequent cause of death in middle-aged and older adults in most industrialised countries, acute myocardial infarction (hereafter AMI) is the main cause of mortality among coronary heart disease patients (OECD, 2015b; Sans et al., 1997; WHO,

* Correspondence to: Lien Nguyen, Centre for Health and Social Economics - CHESS, National Institute for Health and Welfare (THL), Mannerheimintie 166, FI-00270 Helsinki, Finland. E-mail: lien.nguyen@thl.fi.

Published: Online April 2018. dx.doi.org/10.5617/njhe.4538 
2002). Around 1.7 million patients (about 200 per 100000 population) were discharged from hospitals with AMI as the main diagnosis in OECD countries in 2007 (OECD, 2010), and the average length of stay for AMI patients in the OECD countries in 2013 was 6.8 days (OECD, 2015b). These facts indicate that treating AMI uses a lot of resources in healthcare systems.

AMI caused some 18.3-56.9 deaths per 100000 population in the EU15 in 2013 (OECD, 2015b), ${ }^{1}$ while the AMI 30-day case fatality rate varied from 7.1 to $19.1 \%$, regardless of where fatalities occurred (OECD, 2015a). There is sound evidence from randomised clinical trials (RCTs) that the mortality of AMI patients can be reduced with appropriate treatment (Afilalo et al., 2008; Roberts et al., 2007). To guide the use of these treatments and prevent subsequent cardiovascular events in patients discharged after AMI, national and international guidelines have been published (Jones et al., 2013; Niemelä et al., 2014; Steg et al., 2012; Tierala et al., 2011).

The evaluation of treatments in health care has increasingly focused on effectiveness and service costs (i.e. the cost-effectiveness of treatments). There is clear RCT-based evidence that lipid-lowering therapy reduces the risk of recurrent $\mathrm{CHD}$ and improves survival in patients after infarction (LaRosa et al., 1999). The results of economic modelling from meta-analyses of RCTs show that statin therapy in secondary prevention of CHDs is likely to be considered cost-effective (Franco et al., 2005; Ward et al., 2007). Recently, several studies have assessed the individual contribution of treatment technologies in reducing mortality (case-fatality) among AMI patients (Capewell et al., 1999; Laatikainen et al., 2005). In these studies, using mainly meta-analyses of published RCT studies, the authors had determined the absolute mortality benefit of each technology used as a risk factor reduction indicator.

Ideally, measurement of effectiveness and cost-effectiveness would be based on RCTs. However, the use of RCTs for evaluating the effects of health care interventions on health benefits and on costs involves a range of challenges. First, such studies are expensive, difficult and sometimes unethical. Second, since RCTs are conducted under 'laboratory conditions', they do not reveal the true effectiveness but only the efficacy of services. Third, RCTs on health care interventions are often undertaken for a particular target population using strict inclusion criteria, so it is difficult to generalise the results beyond the trial settings. Moreover, most of studies investigating the effects of statin treatment are funded by the pharmaceutical industry (Franco et al., 2005). The type of research financing might affect whether study results are able to remain objective or unbiased. For example, CataláLópez and his colleagues (2013) found that studies funded by the pharmaceutical industry generally favour the cost-effectiveness profile of their products.

Cutler and McClellan (2001) argued that new technologies can affect the medical system through the treatment substitution effect (i.e. they substitute for old technologies) or through the treatment expansion effect (i.e. they lead more people to be treated for disease). The expansion effect is considered a key factor in the failures and benefits of technological innovation, since expanding treatment to more people is beneficial only when treatment is effective (Cutler and McClellan, 2001). There have been numerous studies from various perspectives in Finland exploring the use of statins and the effects of statin treatment among different patient groups, while extensive public debate about the benefits and disadvantages of statin use has been ongoing (Aarnio et al., 2014; Aarnio et al., 2015; Haukka et al., 2012; Huupponen et al., 2012; Ruokoniemi et al., 2011). Statins were rather expensive when introduced in the mid-1980s in Finland but are quite cheap now (Martikainen, 2012; Nguyen

\footnotetext{
${ }^{1}$ The EU15 consisted of the following 15 countries: Austria, Belgium, Denmark, Finland, France, Germany, Greece, Ireland, Italy, Luxembourg, the Netherlands, Portugal, Spain, Sweden and the United Kingdom.
} 
et al., 2016). Statin use after AMI has been found to improve survival among AMI patients, suggesting that as a low-cost treatment it can be highly effective, thus justifying an expansion of statin treatment to more people (Ward et al., 2007). Moreover, the use of noninvasive treatments innovated by new technology, such as aspirin, ACE inhibitors and beta blockers, can also reduce the additional benefit of expensive treatments with old technology (e.g. invasive operations (Stukel et al., 2005)), which may have brought about a reduction in healthcare costs for patients. We further argue that 'low-tech' statin treatment can both reduce healthcare resources and improve survival among AMI patients.

In evaluating the overall effectiveness and costs of medical technologies, one possibility that saves time and is less expensive than an RCT would be to use real-world observational data. There is a need to analyse longer periods of time in many cases because RCTs often have a relatively short follow-up. Observational data are considered appropriate alternative to explore the real-world effectiveness of interventions involving a long period of time (Malminvaara, 2016). Using available observational data, we are not able to incorporate the aspect of quality of life into the study, but we can still appraise the impact of low-tech statin treatment on mortality or longer life and determine the value of the output from the healthcare sector. The aim of this study was to evaluate the effects of statin treatment on two outcomes, mortality and use of healthcare resources, in a one-year followup after discharge from a hospital among AMI patents, using administrative register-based data that stretch from cohort year 1998 to 2012 and cover all new AMI patients in Finland. We further investigated the cost-effectiveness of statin use among these patients during the specified period when statin use became more common and rapidly increased in Finland.

\section{Data and variables}

\section{Primary and matched study data}

Both our study data were from the PERFECT AMI comparison database, which has been constructed by linking the Finnish Hospital Discharge Register with other official registers (Appendix A) (Häkkinen et al., 2011). This database included patients aged 40-84 hospitalised for AMI who were discharged from any Finnish hospital with a main discharge diagnosis of I21 or I22 according to the International Classification of Diseases, Tenth revision (ICD-10). To ensure greater comparability, the database excluded patients if (i) they had been hospitalised for AMI during the previous year (i.e. 365 days), or (ii) their length of stay during the first hospital episode was longer than 90 days, or (iii) they had been in long-term care before the index hospitalization.

The PERFECT AMI comparison database included a total of 117541 AMI hospital discharges that occurred during the period 1998-2012. Of these patients, 85.2\% were discharged from a hospital within 90 days after the beginning of the first AMI care episode $(\mathrm{N}=100$ 018). This patient population became the base data ( $\mathrm{N}=93$ 123) after applying our criteria for choosing study patients: they had to be alive at home at least seven days (one week) after discharge without returning to hospital care during this period. After this, we selected those who had had AMI for the first time and had not used statins before AMI, and we then followed them for one year (365 days). Thus, to get the primary data ( $\mathrm{N}=60404)$, in total $48.6 \%$ were excluded from the PERFECT AMI comparison data (Figure 1). 
Figure 1: Flow chart for the two AMI study data sets used in the analysis, 1998-2011

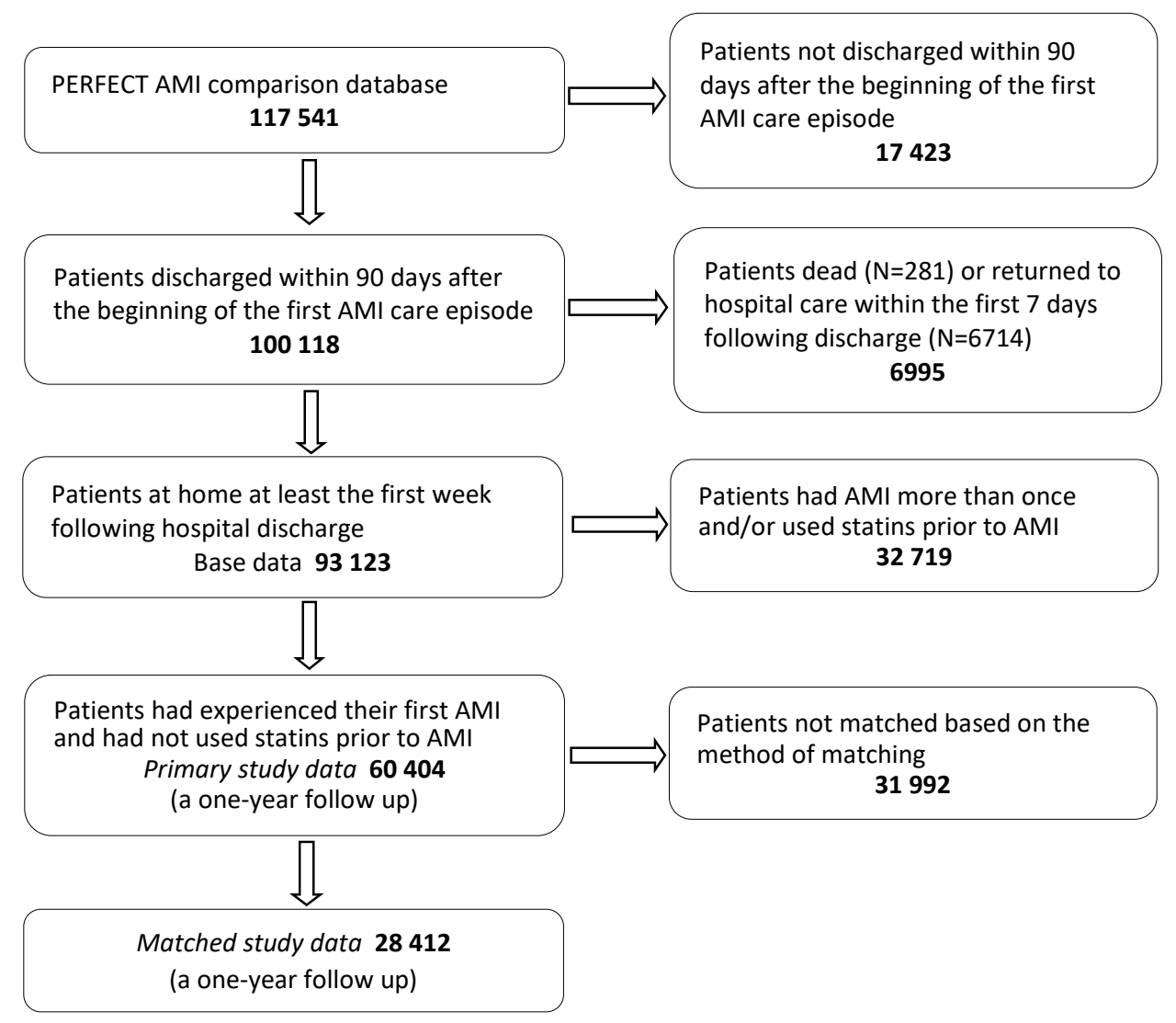

Patients are not typically randomly selected for comparative groups when using observational data in a non-experimental research design to assess the effects of interventions, measures or clinical practices. Sample selection bias may bring about incorrect conclusions, though it could be reduced by using matching econometrics. The basic idea of the matching method is to replace randomisation and to establish experimental conditions in the context of an observational study by finding untreated individuals (controls) that are similar to treated individuals (cases) in terms of their matching variables. Hence, to reduce selection-related bias and to better adjust for confounders, we also employed another data set in the analysis. Based on the primary data ( $\mathrm{N}=60404)$, we matched statin users with statin non-users to obtain the matched data ( $\mathrm{N}=28412)$, using matching techniques based on propensity score analyses (e.g. Guo and Fraser, 2014; Rosenbaum and Rubin, 1983).

Use of statins, i.e. the treatment variable, was binary and was defined as statins purchased within the first seven days after discharge according to medical purchasing information linked to the Social Insurance Institution (SII) register in Finland. The probabilities of treatment (i.e. the use of statins during the first seven days following discharge) were predicted by propensity scores. We first performed 14 propensity score analyses by year to obtain 14 matched samples, and then we pooled these samples to get the matched data for the study period 1998-2011 ( $\mathrm{N}=28$ 412, aged 40-84). The propensity scores were computed by 14 logistic regressions, each included in the model 46 matching variables (male gender, seven age groups, 20 hospital regions, 14 comorbidities, total number of care days during the year prior to the follow-up, use of invasive revascularization 
procedures such as a coronary artery bypass grafting (CABG) and a percutaneous coronary intervention (PCI), use of ACE inhibitors, and use of beta blockers) (Appendix B).

To match treated patients with untreated patients, we used the nearest neighbour method without replacement in descending order and on the common support with a calliper of 0.004. Overall, a calliper can have a maximum width of 0.20 standard deviations of the logit of the estimated score (Cochran and Rubin, 1973). Since a narrow calliper can improve the performance of propensity score matching by greatly reducing bias and giving closer matches (Lunt, 2014), we chose a tighter calliper than the recommended calliper. The calliper of 0.004 was chosen after many tests for differences in the means of the matching covariates included in the logistic regressions. ${ }^{2}$ The degree to which the matching had generated the matched data that balanced the measured covariates between treated and untreated patients was assessed using $\chi^{2}$-tests and paired t-tests. Because propensity scores are also balancing scores, the distribution of observed baseline covariates between treated and untreated patients are similar, which was also found from our matched data (Appendix C).

\subsection{Dependent and explanatory variables}

Two main health outcomes that were explored before the cost-effectiveness of statin use was realised were all-cause mortality and healthcare costs during a one-year follow-up after hospital discharge. Healthcare costs included the costs of hospital care (inpatient and outpatient care of hospitals as well as nursing homes) and the costs of prescribed medicines covered by the SII. The costs of hospital care in the PERFECT database are calculated according to diagnosis-related groups (DRGs) based on available cost information and the per diem rate for each treatment case (Peltola et al., 2011). Healthcare costs were deflated to 2011 values using Statistics Finland's public expenditure price index (the part covering municipal health care) (Statistics Finland, 2016b). We defined a statin user (a statin nonuser) as a patient who had purchased (did not purchase) statins within the first week after discharge, which was recorded by the medical purchasing register of the SII.

With the exception of time (described below), 48 covariates were used in the models. They were statin use, male gender, seven 5-year interval age groups, 14 comorbidities (see Peltola et al., 2011, Table 4), 20 hospital regions, use of invasive revascularization procedures during the first hospital episode (a coronary artery bypass grafting (CABG) and a percutaneous coronary intervention (PCI)), use of medicines (ACE inhibitors and beta blockers) during the first week after hospital discharge or during the year prior to the followup, and use of healthcare services (the number of care days during the year prior to the follow-up and the length of hospital stay before hospital discharge) (Appendix C). 'Chronic coronary heart disease' was excluded because almost every treated patient had the disease. The first two youngest groups aged 40-44 and 45-49 were combined, since their annual proportions in the study data were small.

There have been large differences in physicians' practices, the use of effective treatments, and the supply of revascularisation procedures between regions in treating AMI over the study period in Finland (Häkkinen et al., 2011). These regional factors can

\footnotetext{
${ }^{2}$ After running a logistic regression using 46 matching variables described above and the primary data ( $\mathrm{N}=60$ 404) (Appendix B), we computed the maximum width of the calliper. We then specified an overall value that was smaller than that maximum width. Each time, when a logistic regression was estimated (using year-level data), the overall calliper was used with other criteria (no replacement, descending order and the common support) to match statin users to statin non-users and to obtain a matched sample. We pooled 14 matched samples and checked the balance of covariate proportions between statin users and statin non-users in the pooled matched data $(\mathrm{N}=28$ 412). These steps had been conducted many times with different values of the calliper until the balance of covariate proportions satisfied us.
} 
influence the association between utilisation and/or costs of hospital care and the survival of patients. The effects of the regional factors were accounted for by 21 dummy variables describing hospital regions responsible for providing hospital care services in Finland. Descriptive statistics of variables used in the study by study data and patient groups are introduced in Appendix C.

\subsection{Analytical methods}

\section{Models}

According to the primary data, the proportions of patients having bought statins within the first week after discharge gradually increased from 1998 to 2011: 25-40.3\% (under 50\%) from 1998-2001, 51.7-74.6\% from 2002-2007, and 79.8-85.1\% (80\% at the minimum) from 2008-2011 (Figure 2). Due to the rather long study period and the increased proportions of statin users over the study period, both primary and matched data were analysed for these subperiods in addition to the entire period.

Figure 2: Number of AMI patients and the proportion of AMI patients purchasing statins according to the primary data $(\mathrm{N}=60404), 1998-2011$ (a one-year follow-up)

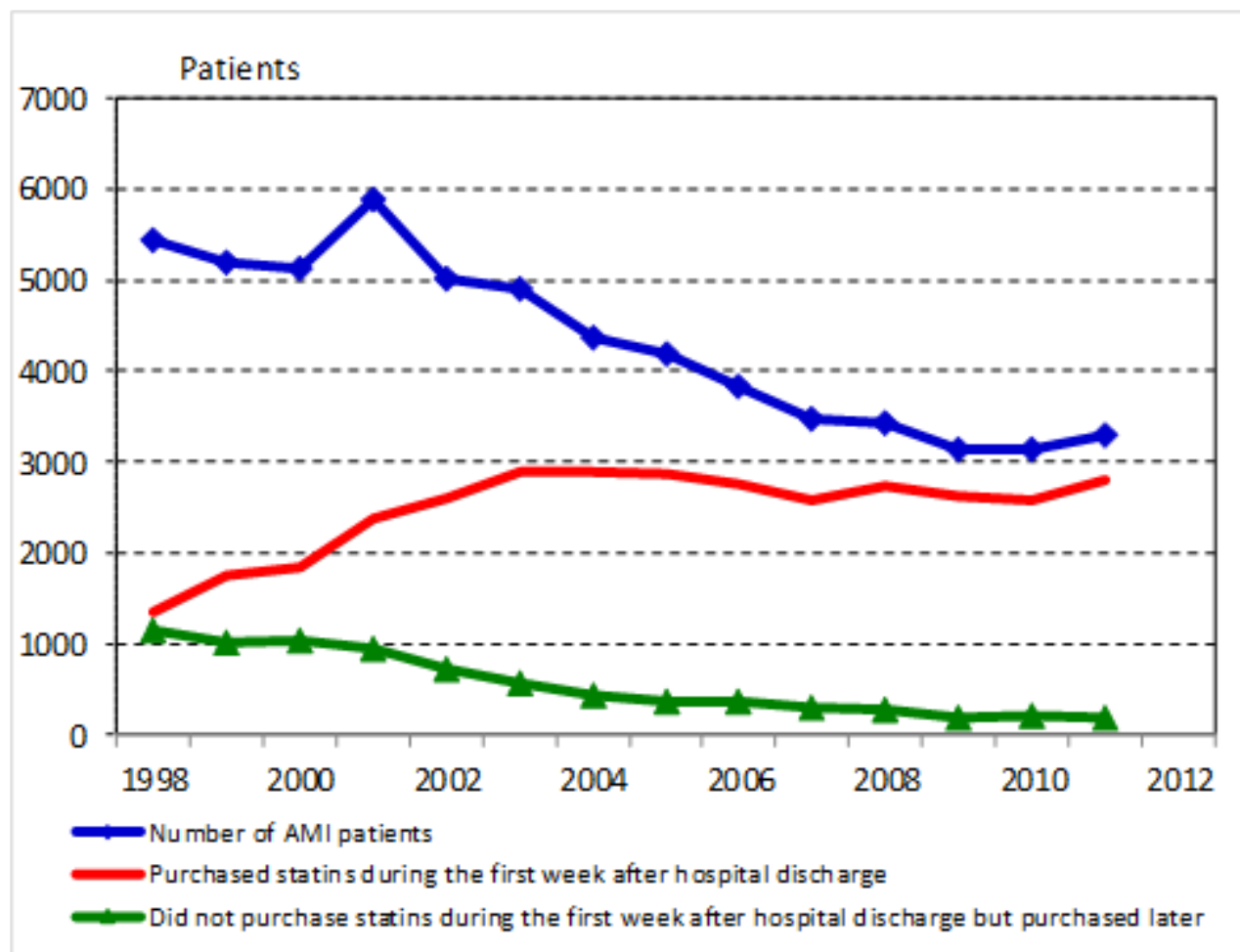

As AMI patients' one-year mortality was specified as binary, we used the logit model to explain mortality risk. To estimate healthcare costs incurred during the one-year follow-up period, we applied the generalised linear model (GLM) with a log-link and the gamma distribution (Hardin et al., 2007). In addition, as another approach, to evaluate the association between the use of statins and one-year mortality, we performed Cox regression analyses (Cox, 1972). In the Cox regression model, one-year mortality was defined and computed as the number of days within which a patient succumbed after hospital discharge. 
Since our main interest was the effect of statins purchased in the first week after hospital discharge on the outcome variables, below we only report the estimation results of statin use, such as the marginal effects of statin use on mortality and healthcare costs from the estimated models. An estimated marginal effect of statin use (a binary explanatory variable) on mortality (a binary dependent variable) from the logit model measured a discrete change in mortality, i.e. how many percentage points the predicted probabilities of mortality changed as the variable for statin use changed from 0 (a statin non-user) to 1 (a statin user). The marginal effect of statin use on healthcare cost (a continuous variable) described how much the predicted healthcare cost changed when the variable for statin use changed from 0 to 1 .

\section{Cost-effectiveness analysis of statin use}

In assessing the cost-effectiveness of statin use, the mortality risk and healthcare costs estimated for statin users were compared to mortality risk and healthcare costs for statin non-users. We made use of the estimated marginal effects of statin use on mortality from the logit models of mortality and the estimated healthcare costs from the GLMs of healthcare costs. Information on life expectancy of the general population at birth for each year from 1998 to 2012 by age and gender was collected from Statistics Finland (2016a). This cost-effectiveness analysis was not conducted from the societal perspective (Gold et al., 1996) because we took into account only the health services sector (hospital care and prescribed medicines). The effect of statin use on mortality, i.e. the health benefit associated with statin use, was measured as the number of life years (LYs) that would have been saved if the mortality risk would be reduced according to the estimated marginal effects of statin use on mortality for the entire period and the three subperiods as well.

We defined gender-standardised life expectancy of an average AMI patient by 10year interval age groups (overall and also for the entire period and the subperiods). Based on these figures and on the estimated marginal effects of statin use on one-year mortality, we computed additional LYs due to avoided deaths by gender and age group. Total LYs gained were obtained by weighting gender and age groups according to their proportions in each data set. After this, additional LYs per average AMI patient and weighted healthcare costs of an additional LY were obtained for the entire period and subperiods. The costeffectiveness ratio in this study was defined as healthcare costs incurred for an additional $L Y$, which could be specified as $\left(H C_{1}-H C_{0}\right) /\left(L E_{1}-L E_{0}\right)$, where $1=$ with statin use and $0=$ without statin use, $\mathrm{HC}=$ healthcare costs, and LE=life expectancy. We computed the LYs gained per average AMI patient and healthcare costs per LY gained without using any discount rates and also with a 3\% discount rate. 


\section{Results}

\subsection{Statin use and mortality}

The estimation results from the logit models indicate that the use of statins was negatively associated with the one-year mortality of AMI patients for all analysed periods (Table 1). Based on computed marginal effects, according to the primary data statin users (those who purchased statins within the first week following discharge) had a mortality risk on average 2.7-3.1 percentage points less than the statin non-users (those who did not purchase statins within the first week following hospital discharge but did so later); the corresponding risk figures for the matched data were 1.5-3.6 percentage points (Table 1). For the entire period 1998-2011, the computed marginal effects of statin use on mortality were -0.031 from the primary data and -0.024 from the matched data (Table 1$)$. Using these two marginal effects to measure the impact of statin treatment on AMI patients, i.e. the number needed to treat (NNT), we could say that to prevent 10 deaths among AMI patients, it would be necessary to get 330-420 AMI patients - those who did not buy statins during the first week following hospital discharge but did so later-to buy statins immediately within one week of hospital discharge. ${ }^{3}$

Table 1: Marginal effects of statin use on mortality and on healthcare cost using primary data $(\mathrm{N}=60404)$ and matched data $(\mathrm{N}=\mathbf{2 8} 412)$

\begin{tabular}{|c|c|c|c|c|c|c|}
\hline \multirow{2}{*}{$\begin{array}{l}\text { Period of time } \\
\text { and study data }\end{array}$} & \multicolumn{3}{|c|}{ Mortality } & \multicolumn{3}{|c|}{ Healthcare cost } \\
\hline & Coefficient & \multicolumn{2}{|c|}{$\begin{array}{c}\text { 95\% Confidence } \\
\text { Interval }\end{array}$} & Estimate & \multicolumn{2}{|c|}{$\begin{array}{c}\text { 95\% Confidence } \\
\text { Interval }\end{array}$} \\
\hline \multicolumn{7}{|l|}{ 1998-2011 } \\
\hline Primary data & $-0.0306^{* * *}$ & -0.0355 & -0.0256 & $916^{*}$ & 100 & 1731 \\
\hline Matched data & $-0.0241^{* * *}$ & -0.0300 & -0.0181 & $309^{\mathrm{NS}}$ & -781 & 1400 \\
\hline \multicolumn{7}{|l|}{ 1998-2001 } \\
\hline Primary data & $-0.0302^{* * *}$ & -0.0402 & -0.0202 & $2774^{* * *}$ & 1359 & 4190 \\
\hline Matched data & $-0.0152^{* * *}$ & -0.0232 & -0.0072 & $2995^{* * *}$ & 1257 & 4734 \\
\hline \multicolumn{7}{|l|}{ 2002-2007 } \\
\hline Primary data & $-0.0313^{* * *}$ & -0.0381 & -0.0244 & $744^{\mathrm{NS}}$ & -448 & 1936 \\
\hline Matched data & $-0.0293^{* * *}$ & -0.0387 & -0.0200 & $-578^{\mathrm{NS}}$ & -2078 & 922 \\
\hline \multicolumn{7}{|l|}{ 2008-2011 } \\
\hline Primary data & $-0.0273^{* * *}$ & -0.0355 & -0.0191 & $-1779^{*}$ & -3291 & -266 \\
\hline Matched data & $-0.0356^{* * *}$ & -0.0544 & -0.0169 & $-2435^{*}$ & -4781 & -90 \\
\hline
\end{tabular}

The estimated Cox regression models produced results that were quite similar to those from the estimated logit models, indicating that the use of statins was statistically

\footnotetext{
${ }^{3}$ The number needed to treat (NNT) is the inverse of the absolute risk reduction (ARR). In this study, NNT is the number of patients (who did not buy statins within the first week after discharge) we need to treat to prevent one additional death. ARR was measured by reduced mortality (i.e. the estimated marginal effects of 0.031 and 0.024 for the entire period 1998-2011, depending on the study data). Hence, the NNTs were 1/0.031 using the primary data and 1/0.024 using the matched data.
} 
associated with improved survival of AMI patients in the one-year follow-up. The estimated hazard ratios are not reported here, though they can be requested from the authors.

\subsection{Statin use and healthcare costs}

Concerning the entire period, a statin user had on average EUR 916 (at 2011 prices) more healthcare costs than a statin non-user from the primary data, while the corresponding cost from the matched data was EUR 309, which was, however, not statistically significant (Table 1). There were increases in healthcare costs, about EUR 2800-3000 per average statin user in the first period (1998-2001). In fact, statin use brought about decreases in healthcare costs, about EUR 1800-2400 per average statin user in the last period (20082011). However, in the middle period (2002-2007), the increase in healthcare costs (EUR 744 per average statin user) and the decrease in costs (EUR 578 per average statin user) were not statistically significant (Table 1).

\subsection{Cost-effectiveness of statin use}

Without using discount rates, the number of additional LYs for an average AMI patient varied between 0.26 and 0.51 by time periods, while with a $3 \%$ discount rate it would vary in a narrower range, between 0.20 and 0.40 (Table 2). For the entire time period, an average AMI patient would gain $0.37-0.42$ years more (without a discount rate) and $0.28-0.33$ years more (with a 3\% discount rate), depending on the study data.

Table 2: Cost-effectiveness analysis of statin use using primary data ( $\mathrm{N}=60 \mathrm{404})$ and matched data $(\mathrm{N}=\mathbf{2 8}$ 412)

\begin{tabular}{|c|c|c|c|c|c|c|}
\hline \multirow[t]{2}{*}{$\begin{array}{l}\text { Period of time and } \\
\text { study data }\end{array}$} & \multirow[t]{2}{*}{$\begin{array}{l}\text { Difference in } \\
\text { mortality (ME) }\end{array}$} & \multicolumn{2}{|c|}{$\begin{array}{c}\text { Life-years gained per } \\
\text { person }\end{array}$} & \multirow[t]{2}{*}{$\begin{array}{l}\text { Cost estimate } \\
\text { per person }^{\mathrm{a}}(€)\end{array}$} & \multicolumn{2}{|c|}{$\begin{array}{l}\text { Costs per life-year } \\
\text { gained }(€)\end{array}$} \\
\hline & & $\begin{array}{c}\text { Without } \\
\text { DR }^{\mathrm{b}}\end{array}$ & $\begin{array}{c}\text { With 3\% } \\
\text { DR }^{\mathrm{b}}\end{array}$ & & $\begin{array}{c}\text { Without } \\
\text { DR }^{\mathrm{b}}\end{array}$ & $\begin{array}{c}\text { With 3\% } \\
\text { DR }^{\mathrm{b}} \\
\end{array}$ \\
\hline \multicolumn{7}{|l|}{ 1998-2011 } \\
\hline Primary data & $-0.0306^{* * *}$ & 0.4195 & 0.3256 & $916^{*}$ & 2183 & 2812 \\
\hline Matched data & $-0.0241^{* * *}$ & 0.3670 & 0.2810 & $309^{\mathrm{NS}}$ & 842 & 1100 \\
\hline \multicolumn{7}{|l|}{ 1998-2001 } \\
\hline Primary data & $-0.0302^{* * *}$ & 0.4227 & 0.3287 & $2774^{* * *}$ & 6562 & 8439 \\
\hline Matched data & $-0.0152^{* * *}$ & 0.2594 & 0.1959 & $2995^{* * *}$ & 11548 & 15290 \\
\hline \multicolumn{7}{|l|}{ 2002-2007 } \\
\hline Primary data & $-0.0313^{* * *}$ & 0.4075 & 0.3178 & $744^{\mathrm{NS}}$ & 1826 & 2341 \\
\hline Matched data & $-0.0293^{* * *}$ & 0.4041 & 0.3159 & $-578^{\mathrm{NS}}$ & saving & saving \\
\hline \multicolumn{7}{|l|}{ 2008-2011 } \\
\hline Primary data & $-0.0273^{* * *}$ & 0.3698 & 0.2835 & $-1779^{*}$ & saving & saving \\
\hline Matched data & $-0.0356^{* * *}$ & 0.5105 & 0.3951 & $-2435^{*}$ & saving & saving \\
\hline
\end{tabular}

Overall, the estimated healthcare costs per LY gained ranged between EUR 840 and EUR 15000 (Table 2). For the entire period, the costs of an additional LY per patient ranged between EUR 840 and EUR 2800. Depending on the discount rates and data sets, the costs 
per additional LY were highest in the first period (1998-2001), about EUR 6600-15 000, while they were indeed negative in the last period (2008-2011), at about EUR -4800 and EUR -6300. The latter negative figures in fact suggest cost savings to the health services sector. The costs of an additional LY computed using the primary data for the middle period 2002-2007 were around EUR 1800-2300 and thus quite similar to the costs computed for the entire period using the primary data (Table 2). ${ }^{4}$

\section{Conclusions and discussion}

The results from this study suggest that statin use was clearly associated with lowered oneyear mortality. The use of statins only marginally increased the use of healthcare resources. The cost estimates of statin use substantially decreased after the first period (1998-2001) and were actually savings (i.e. negative costs) in the third period (2008-2011). Our cost estimates of an additional LY per average AMI patient ranged from EUR 840 to EUR 15000 (at 2011 prices). Indeed, the cost-effectiveness ratios of statin use for the last period (2008-2011) (using both of the study data) and for the middle period (2002-2007) (using the matched data) were negative, meaning cost savings from the treatment of AMI.

In economic evaluations of health interventions, QALYs (quality-adjusted life years), DALYs (disability-adjusted life years) and LYs gained are common outcome measures. In essence, DALY measures health loss in the quality of life, and QALY measures health gain in the same quality of life. Both of these measures involve trade-offs between quantity and quality of health in order to incorporate mortality and morbidity into single numerical units, while LY gained measures mortality taking into account remaining life expectancy (Drummond et al., 2005; Robberstad 2009). It was argued that quality adjustment of life years would not considerably change the estimated level of costeffectiveness and thus would not make much difference for priority setting; in most cases, rather than costs per QALY, costs per LY can be used (Chapman et al., 2004). We might also argue that our crude estimates of population health (the estimated costs per LY gained due to deaths averted) are adequate to suggest priority setting and to allocate healthcare resources for treating AMI with statins if they are considered to be cheap and effective.

In the UK, the NICE cost-effectiveness threshold has typically been between GBP 20000 and GBP 30000 per QALY gained (NICE, 2004), while a central or 'best' threshold estimate of GBP 12936 per QALY measuring its marginal cost (at 2008 expenditure and according to 2008-2010 mortality) has been recently introduced (Claxton et al., 2015). A threshold of EUR 80000 per QALY was generally proposed in the Netherlands (Cleemput et al., 2011), and that of DKK 88000 per QALY as defined for Denmark (Gyrd-Hansen, 2003). In Sweden, a value of SEK 500000 per QALY was regarded as a reasonable level in debate (Johannesson, 2001) and was recommended by the National Board of Health and Welfare (Socialstyrelsen, 2007), while a value of SEK 655000 was suggested as the reference threshold for the healthcare sector in the short term (Persson and Hjelmgren, 2003). Estimates for thresholds per QALY from a recent study were JPY 5 million for Japan, GBP 23000 for the UK, AU\$ 64000 for Australia, and US\$ 62000 for the US (Shiroiwa et al., 2010). In Finland, no willingness-to-pay threshold has been defined that would be considered when assessing the cost-effectiveness of treatments, although in research a threshold of EUR 20000 per QALY has been used (Aarnio et al., 2015) and the value of EUR 30000 as the maximum threshold per QALY (Soini et al., 2015).

The meta-analysis of RCT studies in the UK indicated that in the secondary prevention of coronary diseases, the estimated cost per QALY would range between GBP

\footnotetext{
${ }^{4}$ The marginal effects of statin use on healthcare costs in the middle period 2002-2007 and in the first period 1998-2001 using the matched data were not statistically significant at the 0.05 level (Table 1).
} 
10000 and GBP 17000 for patients aged 45-85 (Ward et al., 2007). Regarding these cost figures and the fact that our AMI patients aged 40-84 were of similar ages, only the estimated costs per LY gained for the first period (1998-2001) using the matched data were close to the boundary values, while the other estimated costs per LY gained were actually smaller than the lower limit value of the cost interval above. If only using the NICE costeffectiveness threshold (NICE, 2004) and the cost estimates per QALY from Wald and colleagues (2007) as well as arguing that LYs gained in our study are an adequate outcome measure, the cost range EUR 840-8400 per additional LY implies acceptable use of National Health Service resources for treating AMI in Finland. Being close to the cost range GBP 10 000-17 000 estimated by Ward and colleagues (2007), our larger cost range of EUR 12 000-15 000 from using the matched data could be acceptable by the arguments introduced above. Furthermore, this estimated cost range suggests that our matching analysis was reliable because we obtained good matched study data, by which we obtained cost estimates that were similar to those obtained from the meta-analysis of the RCT studies (Ward et al., 2007).

We did not compute confidence intervals for our estimated cost-effectiveness ratios (see the last two columns in Table 2). In fact, the healthcare cost estimates, with their 95\% confidence intervals, were obtained from the estimated models (Table 1); but we were not able to obtain 95\% confidence intervals or statistically significant levels for the number of LYs gained per person (i.e. the denominator of the cost-effectiveness ratio). Empirical research has referred to four methods developed from RCTs: the box method, the Taylor series method, the non-parametric bootstrap, and the Fieller theorem method (see e.g. Polsky et al., 1997). However, by nature the confidence intervals of the number of LYs gained could not be computed since we utilised information on life expectancy for the general population provided by Statistics Finland.

The rate of statin use among the study patients increased from 25\% in 1998 to $80 \%$ in 2008 and was about 85\% in 2011 (Figure 2). Taking into account those who had used statins before AMI, the rate of statin use after AMI was 90-92\% in 2008-2013 (Nguyen et al., 2016). Over the study period, the costs of statins used in outpatient care had decreased due to the introduction of generic substitution in 2003, a reduction in wholesale prices, and the introduction of the reference price system in 2009 (Martikainen, 2012; Nguyen et al., 2016). Treatment recommendations (e.g. that patients with myocardial infarction and unstable angina pectoris should use statins) (Tierala et al., 2011; Niemelä et al., 2014) had also affected statin usage. In line with the objective of improved population health and a general view of equality, with the expansion of statin use socioeconomic differences in the use of statins among different patient groups have also narrowed over time (Häkkinen 2013). Considering these facts, we think that the cost estimates per LY gained for the last period 2008-2011 (by both study data) presenting cost savings could be considered as the most presentative for the present time. Therefore, the result for the last period would be the most relevant for priority setting today, while the cost estimates per LY gained in the first period (1998-2001) representing cost increases would not be adequate.

Our computed healthcare costs per LY gained could be overestimated due to the methods used. Applying the method that Statistics Finland has used (Nieminen, 2005) and using the oldest age group 80-84 years of the oldest cohort 1998 in our primary data, we found that life expectancy of AMI patients aged 80-84 years was about 5.05 years, while that of the same age group in the general population was 6.71 years. The oldest cohort and the oldest age patient group in the primary data were used because $97 \%$ of this oldest age group in the primary data had died by 31.12.2014. Thus, knowing their actual life expectancy, we were able to compute the exact number of years that they lived. While the younger cohorts could have better survival than the older cohorts due to improved quality 
of care over time, the younger cohorts' and also younger patients' medical profiles may also be different from those of older cohorts and those of older or ageing patients. Estimated life expectancies of AMI patients may also influence evidence-based treatment for AMI (Ko et al., 2014). Our rather long study period, 1998-2011, suggests that patients who survived in the first week after hospital discharge in the last period (2008-2011) may have very different characteristics than those corresponding patients in the middle period (2002-2007) or in the first period (1998-2001). Thus, our cost estimate range of a LY gained could be regarded as much larger than the cost range that could have accounted for the greater severity of illness and lower life expectancies of AMI patients who survived.

We should also point here to other potential limitations in the present study. First, this study is based on observable data from administrative registers. We were not able to control for all potential factors, even though we used two large data sets, with a substantial number of patient-level and region-level covariates and comorbidities in the analysis, accounting for case-mix severity and analysing both of the data sets by subperiods. Second, since our register-based data did not include any information on patients' socioeconomic status and lifestyles that could be positively associated with patients' decisions to buy statins or to seek hospital care, we were not able to further control the effects of statin use on survival and hospital care.

Irrespective of the limitations mentioned, this study still has several strengths. To our knowledge, this is the first study to have assessed the cost-effectiveness of statin treatment for AMI in secondary prevention using large-scale patient-level data from the real world. We were able to obtain relevant and justifiable estimates on the relationship between statin use and the outcomes, using not only primary register-based data but also the data generated by matching econometrics. Our estimated healthcare costs per LY gained suggest that statin use in treating AMI is very cost-effective, providing real-life evidence of the costeffectiveness of statin treatment as a cheap but efficient medical intervention. Our rather long study period may suggest that the cost estimates per LY gained, especially those for the first period, could be overestimated, as the life expectancy of AMI patients is likely shorter than that of the general population. However, the cost results for the last period presenting cost savings would be the most relevant for priority setting at the present time.

\section{Acknowledgements}

The study was financially supported by the Social Insurance Institution of Finland (through the Research Fund KKRL) and the National Institute for Health and Welfare (THL). The views expressed are solely those of the authors.

We would like to thank the participants at the NHESG Meeting 2015 and the EuHEA Conference 2016 for feedback and two anonymous referees for valuable comments on the earlier version of the paper.

\section{Conflict of interest}

We declare that we do not have any conflict of interest.

\section{References}

Aarnio, E. J., Martikainen, J. A., Helin-Salmivaara, A. et al. (2014). Register-based predictors of adherence among new statin users in Finland. Journal of Clinical Lipidology, 8(1), 117-125. 
Aarnio, E., Korhonen, M. J., Huupponen, R. et al. (2015). Cost-effectiveness of statin treatment for primary prevention in conditions of real-world adherence - Estimates from the Finnish prescription register. Atherosclerosis, 239(1), 240-247.

Afilalo, J., Duque, G., Steele, R. et al. (2008). Statins for secondary prevention in elderly patients: a hierarchical bayesian meta-analysis. Journal of the American College of Cardiology, 51(1), 37-45.

Robberstad, B. (2009). QALYs vs. DALYs vs. LYs gained: What are the differences, and what difference do they make for health care priority setting? Norsk Epidemiologi, 15(2), 183-191.

Capewell, S., Morrison, C. E. and McMurray, J. J. (1999). Contribution of modern cardiovascular treatment and risk factor changes to the decline in coronary heart disease mortality in Scotland between 1975 and 1994. Heart, 81(4), 380-386.

Catalá-López, F., Sanfélix-Gimeno, G., Ridao, M. et al. (2013). When are statins cost-effective in cardiovascular prevention? A systematic review of sponsorship bias and conclusions in economic evaluations of statins. PLoS One, 8(7), e69462.

Chapman, R. H., Berger, M., Weinstein, M. C. et al. (2004). When does quality-adjusting life-years matter in cost-effectiveness analysis? Health Economics, 13(5), 429-436.

Claxton, K., Martin, S., Soares, M. et al. (2015). Methods for the estimation of the National Institute for Health and Care Excellence cost-effectiveness threshold. Health Technology Assessment, 19(14), 1-503, v-vi. doi: 10.3310/hta19140.

Cleemput, I., Neyt, M., Thiry, N. et al. (2011). Using threshold values for cost per quality-adjusted life-year gained in healthcare decisions. International Journal of Technology Assessment in Health Care, 27(01), 71-76.

Cochran, W. G. and Rubin, D. B. (1973). Controlling Bias in Observational Studies: A Review. Sankhya: The Indian Journal of Statistics, Series A (1961-2002), 35(4), 417-446.

Cox, D. R. (1972). Regression models and life tables (with discussion). Journal of the Royal Statistical Society, Series B 34, 187-220.

Cutler, D. M. and McClellan, M. (2001). Is technological change in medicine worth it? Health Affairs, 20(5), 11-29.

Drummond, M. F., Sculpher, M. J., Torrance, G. W. et al. (2005). Methods for the economic valuation of health care programmes (3rd ed). Oxford: Oxford University Press.

Franco, O. H., Peeters, A., Looman, C. W. et al. (2005). Cost effectiveness of statins in coronary heart disease. Journal of Epidemiology and Community Health, 59(11), 927-933.

Gold, M. R., Siegel, J. E., Russell, L. B. et al. (1996). Cost-effectiveness in health and medicine: report of the panel on cost-effectiveness in health and medicine. New York, NY: Oxford University Press.

Guo, S. and Fraser, M. W. (2014). Propensity score analysis: Statistical methods and applications (2nd ed). SAGE Publications.

Gyrd-Hansen, D. (2003). Willingness to pay for a QALY. Health Econnomics, 12(12), 1049-1060.

Hardin, J. W., Hilbe, J. M. and Hilbe, J. (2007). Generalized linear models and extensions (2nd ed). College Station, TX: Stata Press..

Haukka, J., Niskanen, L., Partonen, T. et al. (2012). Statin usage and all-cause and disease-specific mortality in a nationwide study. Pharmacoepidemiology and Drug Safety, 21(1), 61-69.

Huupponen, R., Korhonen, M. J. and Helin-Salmivaara, A. (2012). Statiinien käyttö ja kustannus (STATEAM)-hankkeesta.

http://www.kela.fi/documents/10180/243147/Huupponen_statiini.pdf/1b92d668-151b-4a4bac98-4a2549bfb22e (Accessed 15 January 2016).

Häkkinen, U., Hartikainen, J., Juntunen, M. et al. (2011). Analysing current trends in care of acute myocardial infarction using PERFECT data. Annals of Medicine, 43(Suppl 1), S14-S21. 
Häkkinen, U. (2013). Onko erikoissairaanhoidon kustannuksissa ja vaikuttavuudessa sosioekonomisia eroja? Esimerkkinä sydäninfarktin hoito. Esitelmä Terveystaloustieteen päivillä 2013. Helsinki.

Jones, K., Saxon, L., Cunningham, W. et al. (2013). Secondary prevention for patients after a myocardial infarction: summary of updated NICE guidance. BMJ, 347, f6544. doi: https://doi.org/10.1136/bmj.f6544.

Johannesson, M. (2001). Kostnadseffektivitet: För prissättning, subventionering eller terapival? I: B. Jönsson B (redaktör), Läkemedel: Kostnad eller resurs för sjukvården? Stockholm: Ekonomiska forskningsinstitutet vid Handelshögskolan i Stockholm.

Ko, D. T., Austin, P. C., Tu, J. V. et al. (2014). Relationship between care gaps and projected life expectancy after acute myocardial infarction. Circulation: Cardiovascular Quality and Outcomes, 7(4), 581-588.

Laatikainen, T., Critchley, J., Vartiainen, E. et al. (2005). Explaining the Decline in Coronary Heart Disease Mortality in Finland between 1982 and 1997. American Journal of Epidemiology, 162(8), 764-773.

LaRosa, J. C., He, J. and Vupputuri, S. (1999). Effect of statins on risk of coronary disease: A metaanalysis of randomized controlled trials. Journal of the American Association, 282(24), 23402346.

Lunt, M. (2014). Selecting an Appropriate Caliper Can Be Essential for Achieving Good Balance With Propensity Score Matching. American Journal of Epidemiology, 179(2), 226-235.

Malmivaara, A. (2016). Clinical Impact Research - how to choose experimental or observational intervention study? Annals of Medicine, 8(7), 492-495. doi: 10.1080/07853890.2016.1186828.

Martikainen, J. (2012). Uusien lääkkeiden markkinoille tulo ja lääkekustannuksiin vaikuttaminen. Helsinki: Kela, Sosiaali- ja terveysturvan tutkimuksia 119.

Nguyen, L., Jurvanen, H., Häkkinen, U. et al. (2016). Lääkkeet sydäninfarktin hoidossa: Statiinihoidon hyödyt ja haitat. Raportti 6/2016. Helsinki: Terveyden ja hyvinvoinnin laitos (THL).

NICE (2004). Guide to the methods of health technology appraisal. London: NICE National Institute for Health and Clinical Excellence.

Niemelä, K., Vikman, S., Kettunen, R. et al. (2014). Sepelvaltimotautikohtaus: epästabiili angina pectoris ja sydäninfarkti ilman ST-nousuja: Käypä hoito - suosituksen päivitystiivistelmä. Duodecim, 130, 1764-1766.

Nieminen, M. (2005). 3/2005 Eläkeikäisten demografiaa, osa IV. Tilastollisesti elettävänä olevat vuodet. http://www.stat.fi/tup/tietoaika/tilaajat/ta_03_05_nieminen.html Väestötieteen salat. Helsinki, Statistics Finland (Accessed 15 January 2016).

OECD (2010). OECD HEALTH DATA. Paris.

OECD (2015a). OECD HEALTH DATA. Paris.

OECD (2015b). Health at a Glance 2015: OECD Indicators. Paris: OECD Publishing.

Peltola, M., Juntunen, M., Häkkinen, U. et al. (2011). A methodological approach for register-based evaluation of cost and outcomes in health care. Annals of Medicine, 43(sup1), S4-S13.

Persson, U. and Hjelmgren, J. (2003). Hälso- och sjukvården behöver kunskap om hur befolkningen värderar hälsan. Läkartidningen, 43(100), 3436-3437.

Polsky, D., Glick, H. A., Willke, R. et al. (1997). Confidence intervals for cost-effectiveness ratios: a comparison of four methods. Health Economics, 6(3), 243-252.

Roberts, C. G., Guallar, E. and Rodriguez, A. (2007). Efficacy and safety of statin monotherapy in older adults: a meta-analysis. The Journals of Gerontology Series A: Biological Sciences and Medical Sciences, 62(8), 879-887.

Rosenbaum, P. R. and Rubin, D. B. (1983). The Central Role of the Propensity Score in Observational Studies for Causal Effects. Biometrika, 70(1), 41-55. 
Ruokoniemi, P., Korhonen, M. J., Helin-Salmivaara, A. et al. (2011). Statin adherence and the risk of major coronary events in patients with diabetes: a nested case-control study. British Journal of Clinical Pharmacology, 71(5), 766-776.

Sans, S., Kesteloot, H. and Kromhout, D. (1997). The burden of cardiovascular diseases mortality in Europe. European Heart Journal, 18(8), 1231-1248.

Shiroiwa, T., Sung, Y. K., Fukuda, T. et al. (2010). International survey on willingness-to-pay (WTP) for one additional QALY gained: what is the threshold of cost effectiveness? Health Economics, 19(4), 422-437. doi: 10.1002/hec.1481.

Socialstyrelsen (2007). Nationella riktlinjer för prostatacancersjukvård - Medicinskt och hälsoekonomiskt faktadokument. Stockholm.

Soini, E. J., Hallinen, T., Sokka, A-L. et al. (2015). Cost-Utility of First-Line Actinic Keratosis Treatments in Finland. Advances in Therapy. Advances in Therapy, 32(5), 455-476. doi: 10.1007/s12325-015-0211-7.

Statistics Finland (2016a). Elinajanodote. PX-Web Statfin. http://pxnet2.stat.fi/PXWeb/pxweb/fi/StatFin/. Helsinki, Statistics Finland; Tilastokeskus (Accessed 15 January 2016).

Statistics Finland (2016b). Hinnat ja kustannukset. PX-Web Statfin. http://pxnet2.stat.fi/PXWeb/pxweb/fi/StatFin/. Helsinki, Statistics Finland; Tilastokeskus (Accessed 15 January 2016).

Steg, P. G., James, S. K., Atar, D. et al. (2012). ESC Guidelines for the management of acute myocardial infarction in patients presenting with ST-segment elevation. The Task Force on the management of ST-segment elevation acute myocardial infarction of the European Society of Cardiology (ESC). European Heart Journal, 33, 2569-2619. doi: 10.1093/eurheartj/ehs215.

Stukel, T. A., Lucas, F. and Wennberg, D. E. (2005). Long-term outcomes of regional variations in intensity of invasive vs medical management of medicare patients with acute myocardial infarction. Journal of the American Association, 293(11), 1329-1337.

Tierala, I., Eskola, M., Ihlberg, L. et al. (2011). ST-nousuinfarkti: Käypähoito - suosituksen tiivistelmä. Duodecim, 127, 1946-1947.

Ward, S., Lloyd Jones, M., Pandor, A. et al. (2007). A systematic review and economic evaluation of statins for the prevention of coronary events. Health Technology Assessment, 11(14), 1-160, iii-iv.

WHO. (2002). The world health report 2002: reducing risks, promoting healthy life. Geneve: World Health Organization.

(C) 2018 by the author(s). This article is an open access article distributed under the terms and conditions of the Creative Commons Attribution license (http://creativecommons.org/licenses/by/4.0/). 


\section{Appendices}

\section{Appendix A: The Finnish health registers used in the study}

\begin{tabular}{|c|c|}
\hline Register & Description (ownership) \\
\hline $\begin{array}{l}\text { Hospital discharge } \\
\text { register }\end{array}$ & $\begin{array}{l}\text { Discharges from all public and private hospitals in Finland. Data since } 1987 . \\
\text { (THL) }\end{array}$ \\
\hline $\begin{array}{l}\text { Data file on coronary } \\
\text { patients }\end{array}$ & $\begin{array}{l}\text { The hospital discharge register incorporates a data file on coronary patients } \\
\text { who have received surgical treatment. The data file contains additional data } \\
\text { collected by means of a separate form on coronary patients in need of } \\
\text { demanding treatment. Data since } 1995 \text {. (THL) }\end{array}$ \\
\hline $\begin{array}{l}\text { Outpatient care in } \\
\text { specialised health care } \\
\text { institutions }\end{array}$ & $\begin{array}{l}\text { Outpatient visits from public hospitals giving specialised health care in } \\
\text { Finland. Data since 1998. (THL) }\end{array}$ \\
\hline Cause-of-death register & Causes-of-death of Finnish citizens since 1969. (Statistics Finland) \\
\hline $\begin{array}{l}\text { Special reimbursements } \\
\text { of medicine }\end{array}$ & Since 1964. (Social Insurance Institution, SII) \\
\hline Prescribed medicine & Since 1996. (Social Insurance Institution, SII) \\
\hline
\end{tabular}

THL = National Institute for Health and Welfare

Source: Häkkinen et al. (2011) 


\section{Appendix B: Tests for differences in the means of the covariates included in the logistic regressions}

\begin{tabular}{|c|c|c|}
\hline \multirow[t]{2}{*}{ Variable $^{\mathrm{a}}$} & \multicolumn{2}{|c|}{$p$-value } \\
\hline & $\begin{array}{l}\text { Primary data } \\
(\mathrm{N}=60404)\end{array}$ & $\begin{array}{l}\text { Matched data } \\
(\mathrm{N}=28 \text { 412) }\end{array}$ \\
\hline
\end{tabular}

Dependent variable (treatment variable): use of statins during the first seven days after discharge

Gender (male)

7 age groups beginning from 50-54 years old until 80-84 years old;

reference age group: 40-49 years old

21 hospital districts or regions ${ }^{\mathrm{b}}$

Number of care days during 365 days prior to the follow-up

PCI (percutaneous coronary intervention) during the first hospital episode

CABG (coronary artery bypass grafting) during the first hospital episode

Use of ACE inhibitors during the first seven days after discharge or during the year prior to the follow-up

Use of beta blockers during the first seven days after discharge or during the year prior to the follow-up

\section{Comorbidities}

Hypertension

$\begin{array}{ll}0.000 & 0.564 \\ 0.000 & 0.784 \\ 0.000 & 0.788 \\ 0.000 & 0.120 \\ 0.000 & 0.971 \\ 0.000 & 0.504 \\ 0.000 & 0.332 \\ 0.000 & 0.651 \\ 0.000 & 0.632 \\ 0.000 & 0.984 \\ 0.000 & 0.241 \\ 0.000 & 0.628 \\ 0.000 & 0.469 \\ 0.000 & 0.502\end{array}$

Atrial fibrillation

0.784

Cardiac insufficiency

0.120

Diabetes mellitus

0.971

Alcoholism

0.504

Atherosclerosis

.332

COPD and asthma

0.632

Dementia

0.984

Depression

Epilepsy

.469

Mental disorders

0.000

0.502

Renal insufficiency

a The number of care days can only receive non-negative integer values. Other
b One explanatory variable (the reference variable) was not used in the models.

c A comorbidity was recorded if prior to the follow-up (1) the patient had a disease-specific primary diagnosis in his/her medical history based on the Finnish Hospital Discharge Register or (2) the patient diagnosed with a certain chronic disease was entitled to special reimbursement for his/her medication from the Finnish Social Insurance Institution (SII) during the previous year or (3) he/she had comorbidity-based medicine purchases during the previous year. 


\section{Appendix C: Descriptive statistics of variables}

\begin{tabular}{|c|c|c|c|c|c|c|c|c|}
\hline \multirow[t]{3}{*}{ Variable } & \multicolumn{4}{|c|}{ Primary data $(\mathrm{N}=60604)$} & \multicolumn{4}{|c|}{ Matched data ( $\mathrm{N}=28$ 412) } \\
\hline & \multicolumn{2}{|c|}{$\begin{array}{l}\text { Cases } \\
(\mathrm{N}=34681)\end{array}$} & \multicolumn{2}{|c|}{$\begin{array}{l}\text { Controls } \\
(\mathrm{N}=25 \text { 723) }\end{array}$} & \multicolumn{2}{|c|}{$\begin{array}{l}\text { Cases } \\
(\mathrm{N}=14206)\end{array}$} & \multicolumn{2}{|c|}{$\begin{array}{l}\text { Controls } \\
(\mathrm{N}=14206)\end{array}$} \\
\hline & Mean & Std dev. & Mean & Std dev. & Mean & Std dev. & Mean & Std dev. \\
\hline \multicolumn{9}{|c|}{ Dependent variables } \\
\hline One-year mortality & 0.035 & 0.183 & 0.119 & 0.324 & 0.056 & 0.230 & 0.083 & 0.277 \\
\hline \multicolumn{9}{|c|}{ Healthcare costs (EUR, at 2011} \\
\hline prices) & 13641 & 40305 & 18190 & 46958 & 18677 & 45895 & 18246 & 48216 \\
\hline \multicolumn{9}{|c|}{ Explanatory variables } \\
\hline Male & 0.694 & 0.461 & 0.596 & 0.491 & 0.631 & 0.483 & 0.637 & 0.481 \\
\hline \multicolumn{9}{|c|}{ Five-year interval age groups ${ }^{\mathrm{a}}$} \\
\hline $50-54$ & 0.106 & 0.308 & 0.063 & 0.244 & 0.088 & 0.283 & 0.086 & 0.280 \\
\hline $55-59$ & 0.133 & 0.339 & 0.076 & 0.265 & 0.101 & 0.302 & 0.105 & 0.306 \\
\hline $60-64$ & 0.142 & 0.349 & 0.092 & 0.289 & 0.119 & 0.324 & 0.123 & 0.329 \\
\hline $65-69$ & 0.142 & 0.349 & 0.112 & 0.316 & 0.135 & 0.341 & 0.137 & 0.343 \\
\hline $70-74$ & 0.149 & 0.356 & 0.165 & 0.371 & 0.172 & 0.377 & 0.166 & 0.372 \\
\hline $75-79$ & 0.131 & 0.338 & 0.208 & 0.406 & 0.171 & 0.377 & 0.170 & 0.376 \\
\hline 80-84 & 0.095 & 0.293 & 0.229 & 0.420 & 0.140 & 0.347 & 0.138 & 0.345 \\
\hline \multicolumn{9}{|c|}{ Hospital districts or regions $(\mathrm{shp})^{\mathrm{b}}$} \\
\hline shp 2 & 0.050 & 0.219 & 0.052 & 0.223 & 0.054 & 0.227 & 0.054 & 0.225 \\
\hline shp 3 & 0.028 & 0.166 & 0.041 & 0.197 & 0.035 & 0.183 & 0.035 & 0.184 \\
\hline $\operatorname{shp} 4$ & 0.081 & 0.273 & 0.080 & 0.271 & 0.080 & 0.271 & 0.081 & 0.273 \\
\hline shp 5 & 0.039 & 0.194 & 0.040 & 0.196 & 0.041 & 0.198 & 0.042 & 0.200 \\
\hline shp 6 & 0.042 & 0.201 & 0.035 & 0.183 & 0.039 & 0.195 & 0.038 & 0.192 \\
\hline shp 7 & 0.028 & 0.166 & 0.038 & 0.192 & 0.031 & 0.174 & 0.030 & 0.172 \\
\hline shp 8 & 0.028 & 0.164 & 0.031 & 0.174 & 0.033 & 0.179 & 0.030 & 0.171 \\
\hline shp 9 & 0.015 & 0.121 & 0.021 & 0.142 & 0.020 & 0.140 & 0.019 & 0.138 \\
\hline shp 10 & 0.035 & 0.185 & 0.048 & 0.214 & 0.041 & 0.197 & 0.042 & 0.201 \\
\hline shp 11 & 0.067 & 0.251 & 0.059 & 0.235 & 0.065 & 0.247 & 0.063 & 0.242 \\
\hline shp 12 & 0.056 & 0.229 & 0.053 & 0.224 & 0.059 & 0.235 & 0.058 & 0.233 \\
\hline shp 13 & 0.050 & 0.217 & 0.044 & 0.205 & 0.046 & 0.210 & 0.046 & 0.210 \\
\hline shp 14 & 0.034 & 0.180 & 0.032 & 0.176 & 0.034 & 0.181 & 0.034 & 0.180 \\
\hline shp 15 & 0.017 & 0.130 & 0.018 & 0.134 & 0.019 & 0.137 & 0.018 & 0.135 \\
\hline shp 16 & 0.069 & 0.254 & 0.077 & 0.267 & 0.075 & 0.263 & 0.076 & 0.265 \\
\hline shp 17 & 0.018 & 0.133 & 0.031 & 0.173 & 0.021 & 0.143 & 0.020 & 0.139 \\
\hline shp 18 & 0.016 & 0.124 & 0.016 & 0.127 & 0.015 & 0.122 & 0.017 & 0.129 \\
\hline shp 19 & 0.027 & 0.163 & 0.026 & 0.159 & 0.028 & 0.166 & 0.027 & 0.161 \\
\hline shp 20 & 0.134 & 0.341 & 0.116 & 0.320 & 0.120 & 0.325 & 0.125 & 0.330 \\
\hline shp 21 & 0.067 & 0.250 & 0.072 & 0.259 & 0.060 & 0.238 & 0.062 & 0.241 \\
\hline
\end{tabular}


Appendix C: Descriptive statistics of variables (continued)

\begin{tabular}{|c|c|c|c|c|c|c|c|c|}
\hline \multirow[t]{3}{*}{ Variable } & \multicolumn{4}{|c|}{ Primary data $(\mathrm{N}=60604)$} & \multicolumn{4}{|c|}{ Matched data $(\mathrm{N}=28$ 412) } \\
\hline & \multicolumn{2}{|c|}{$\begin{array}{c}\text { Cases } \\
(\mathrm{N}=34681)\end{array}$} & \multicolumn{2}{|c|}{$\begin{array}{c}\text { Controls } \\
(\mathrm{N}=25723)\end{array}$} & \multicolumn{2}{|c|}{$\begin{array}{c}\text { Cases } \\
(\mathrm{N}=14206)\end{array}$} & \multicolumn{2}{|c|}{$\begin{array}{c}\text { Controls } \\
(\mathrm{N}=14206)\end{array}$} \\
\hline & Mean & Std dev. & Mean & Std dev. & Mean & $\begin{array}{r}\text { Std } \\
\text { dev. }\end{array}$ & Mean & Std dev. \\
\hline \multicolumn{9}{|l|}{ Cohort years ${ }^{\mathrm{c}}$} \\
\hline year 1999 & 0.050 & 0.219 & 0.134 & 0.340 & 0.104 & 0.305 & 0.104 & 0.305 \\
\hline year 2000 & 0.053 & 0.225 & 0.127 & 0.333 & 0.109 & 0.312 & 0.109 & 0.312 \\
\hline year 2001 & 0.068 & 0.252 & 0.136 & 0.343 & 0.123 & 0.328 & 0.123 & 0.328 \\
\hline year 2002 & 0.075 & 0.263 & 0.094 & 0.292 & 0.107 & 0.309 & 0.107 & 0.309 \\
\hline year 2003 & 0.083 & 0.277 & 0.078 & 0.268 & 0.093 & 0.291 & 0.093 & 0.291 \\
\hline year 2004 & 0.083 & 0.276 & 0.057 & 0.233 & 0.074 & 0.262 & 0.074 & 0.262 \\
\hline year 2005 & 0.083 & 0.275 & 0.051 & 0.220 & 0.066 & 0.248 & 0.066 & 0.248 \\
\hline year 2006 & 0.080 & 0.271 & 0.041 & 0.199 & 0.058 & 0.233 & 0.058 & 0.233 \\
\hline year 2007 & 0.075 & 0.263 & 0.034 & 0.182 & 0.049 & 0.215 & 0.049 & 0.215 \\
\hline year 2008 & 0.079 & 0.270 & 0.027 & 0.162 & 0.040 & 0.196 & 0.040 & 0.196 \\
\hline year 2009 & 0.076 & 0.265 & 0.020 & 0.141 & 0.029 & 0.168 & 0.029 & 0.168 \\
\hline year 2010 & 0.074 & 0.262 & 0.022 & 0.145 & 0.030 & 0.172 & 0.030 & 0.172 \\
\hline year 2011 & 0.081 & 0.273 & 0.019 & 0.137 & 0.029 & 0.169 & 0.029 & 0.169 \\
\hline \multicolumn{9}{|l|}{ Comorbidities } \\
\hline Hypertension & 0.667 & 0.471 & 0.664 & 0.472 & 0.631 & 0.483 & 0.628 & 0.483 \\
\hline Atrial fibrillation & 0.123 & 0.328 & 0.200 & 0.400 & 0.161 & 0.368 & 0.162 & 0.369 \\
\hline Cardiac insufficiency & 0.062 & 0.241 & 0.180 & 0.384 & 0.107 & 0.309 & 0.106 & 0.308 \\
\hline Diabetes mellitus & 0.126 & 0.332 & 0.194 & 0.395 & 0.163 & 0.369 & 0.156 & 0.363 \\
\hline Alcoholism & 0.024 & 0.152 & 0.030 & 0.171 & 0.028 & 0.165 & 0.028 & 0.164 \\
\hline Atherosclerosis & 0.022 & 0.146 & 0.049 & 0.216 & 0.033 & 0.179 & 0.032 & 0.176 \\
\hline Cancer & 0.067 & 0.251 & 0.100 & 0.300 & 0.084 & 0.277 & 0.081 & 0.273 \\
\hline COPD and asthma & 0.128 & 0.334 & 0.168 & 0.374 & 0.148 & 0.355 & 0.146 & 0.354 \\
\hline Dementia & 0.009 & 0.093 & 0.030 & 0.172 & 0.015 & 0.123 & 0.016 & 0.125 \\
\hline Depression & 0.083 & 0.276 & 0.119 & 0.324 & 0.098 & 0.297 & 0.098 & 0.297 \\
\hline Epilepsy & 0.037 & 0.189 & 0.047 & 0.213 & 0.042 & 0.200 & 0.039 & 0.194 \\
\hline Parkinson's disease & 0.008 & 0.091 & 0.019 & 0.136 & 0.012 & 0.109 & 0.013 & 0.112 \\
\hline Mental disorders & 0.038 & 0.190 & 0.075 & 0.264 & 0.052 & 0.223 & 0.051 & 0.219 \\
\hline Renal insufficiency & 0.001 & 0.038 & 0.005 & 0.073 & 0.003 & 0.051 & 0.003 & 0.055 \\
\hline \multicolumn{9}{|l|}{ Other variables } \\
\hline $\begin{array}{l}\text { Number of care days during } 365 \\
\text { days prior to the follow-up }\end{array}$ & 3.5 & 9.5 & 9.4 & 20.8 & 5.0 & 12.8 & 5.2 & 11.7 \\
\hline $\begin{array}{l}\text { CABG (coronary artery bypass } \\
\text { grafting) during the first hospital } \\
\text { episode }\end{array}$ & 0.088 & 0.283 & 0.037 & 0.190 & 0.058 & 0.233 & 0.055 & 0.227 \\
\hline $\begin{array}{l}\text { PCI (percutaneous coronary } \\
\text { intervention) during the first } \\
\text { hospital episode }\end{array}$ & 0.436 & 0.496 & 0.104 & 0.306 & 0.177 & 0.382 & 0.170 & 0.375 \\
\hline $\begin{array}{l}\text { Use of ACE inhibitors during the } \\
\text { first seven days after discharge or } \\
\text { during the year prior to the } \\
\text { follow-up }\end{array}$ & 0.465 & 0.499 & 0.267 & 0.442 & 0.363 & 0.481 & 0.291 & 0.454 \\
\hline $\begin{array}{l}\text { Use of beta-blockers during the } \\
\text { first seven days after discharge or } \\
\text { the year prior to the follow-up }\end{array}$ & 0.835 & 0.371 & 0.608 & 0.488 & 0.789 & 0.408 & 0.658 & 0.474 \\
\hline $\begin{array}{l}\text { Number of hospital days before } \\
\text { hospital discharge }\end{array}$ & 9.0 & 8.3 & 11.9 & 11.2 & 10.1 & 8.8 & 11.0 & 10.5 \\
\hline
\end{tabular}

